\title{
Retinal Vessel Responses to Exercise and Hypoxia Before and After High Altitude Acclimatisation
}

\author{
O. BRINCHMANN-HANSEN, ${ }^{*}$ K. MYHRE, $\dagger$ L. SANDVIK $\ddagger$ \\ Oslo, Norway
}

\begin{abstract}
Summary
Computerised microdensitometry was used to study diameter changes in 93 arterial and 91 venous vessel sites in the retinas of four mountain climbers before and after spending seven weeks in the Himalaya mountains. The vascular response to shortterm strenuous exercise was measured at sea level, to acute hypoxia of simulated altitude of $15,000 \mathrm{ft}(4,572 \mathrm{~m})$ at rest, and to strenuous exercise while acutely exposed to the same hypoxic condition. Before the mountain exposure, retinal vessels constricted during exercise $-1.9 \%$ (arteries); $-3.3 \%$ (veins) and dilated in acute hypoxia 9.4\% (arteries); $8.1 \%$ (veins). Superimposed exercise on hypoxic dilated arteries reduced the vasodilation $(9.4 \%$ to $6 \%)$. After acclimatisation, the same physical work load at sea level constricted the arteries more $(-5.4 \%$ vs $-1.9 \%)$ but did not constrict the veins $(0.2 \%$ vs $-3.3 \%)$. Superimposed exercise on hypoxic dilated vessels, excessively dilated both arteries $(8.4 \%$ vs $6.0 \%)$ and veins $(13.7 \%$ vs $8.4 \%)$, compared to changes seen before the mountain sojourn. This study shows that physical conditioning and long adaptation to hypoxia, significantly change the vascular response of the retina to physical activity both in normal atmospheric conditions and during hypoxic stress. High altitude retinal hemorrhages (HARH) were present in one climber, and the study may indicate why HARH is seen often in young and physical well-trained subjects.
\end{abstract}

Prolonged high altitude exposure produces physiological responses which tend to reduce the hypoxaemia. These responses include both increased oxygen capacity of the blood and increased oxygen delivery to the tissues by a right shift of the oxygen dissociation curve. ${ }^{1,2}$ Furthermore, modification of blood flow also takes place by systemic or local adjustments in various regional vascular systems. In this respect, the retina provides a microvascular bed which is easily accessible for in vivo studies in man. Experimental studies of acute hypoxia ${ }^{3-7}$ and long-term hypoxia in subjects participating in mountaineering expeditions, ${ }^{8-11}$ have documented that hypobaric hypoxia dilates both retinal arteries and veins. Vasodilation and increased blood flow improve oxygen transport to the retina, and as such it represents a beneficial mechanism determined by local needs of the eye.

In physical exercise, being an inevitable part of mountain climbing, there is no local need for adjustments of eye circulation. Cardiac output is, however, augmented to meet the increased demand for muscular blood flow. Possible changes in retinal vessels will then

From: *Department of Ophthalmology, Ullevål, University Hospital; †Royal Norwegian Institute of Aviation Medicine; and $\ddagger$ Medstat, Centre for Medical Statistics, Oslo, Norway.

Correspondence to: Olaf Brinchmann-Hansen MD, Department of Ophthalmology, Ullevål University Hospital, 0407 Oslo 4, Norway. 
reflect the autoregulatory ability of the eye to withstand elevated flow caused by changes in the systemic circulation.

In the present paper, calibre changes of retinal arteries and veins were studied in physical exercise at sea level, in acute exposure to hypoxia, and in physical exercise superimposed on already hypoxic dilated vessels. The subjects were exposed to identical test protocol before and after seven weeks of strenuous mountain climbing in the Himalaya mountains. We observed that high altitude acclimatisation significantly altered the acute response of retinal circulation to physical exercise both in a hypoxic environment and at sea level.

\section{Subjects and methods}

\section{Subjects}

Four male mountaineers, aged 33 (no.1), 42 (no. 2), 64 (no. 3), and 42 (no. 4) (mean: 45) years, were used in the study. One of the subjects (no. 2) lived $800 \mathrm{~m}$ above sea level, while the rest of the group lived at sea level. The youngest climber had not previously been exposed to high altitude, while the others were experienced mountaineers from several expeditions above $5,000 \mathrm{~m}$. None of these expeditions, however, had taken place within the past three years.

General medical and eye examinations were performed, and the subjects were found to be in good health. The blood pressure was measured by auscultation in a sitting position after 10 minutes rest. The systolic pressure averaged $142 \pm 9$ (SD) $\mathrm{mmHg}$ and the diastolic pressure $80 \pm 8 \mathrm{mmHg}$. The intraocular pressure, measured by applanation tonometry in the sitting position, averaged $12 \pm$ $1.4 \mathrm{mmHg}$ (both eyes). Visual acuity was $20 / 20$ in both eyes of all subjects. None of the subjects undertook systematic physical training. However, the maximal aerobic power of the subjects, indirectly assessed, ${ }^{12}$ ranged from $44-58 \mathrm{mlO}_{2} / \mathrm{kg} \cdot \mathrm{min}$, which is above average.

\section{Test protocol}

Identical test protocols were used before and after an expedition to Himalaya, which had involved seven weeks of strenuous climbing. The study included fundus photography (calibre measurements of retinal vessels), blood samples for measuring haemoglobin concentration $(\mathrm{Hgb})$, packed cell volume (PCV), by standard clinical procedures, in addition to physical exercise tests (bicycle ergometer) and exposure to acute hypobaric hypoxia in a low pressure chamber. The protocol was carried out in four steps.

Step 1, 'sea level, rest'. In cycloplegia (cyclopentholati chloridi $1 \%$ and metaoxidrini $10 \%$ ), the fundus in both eyes was photographed after 10 minutes rest in a sitting position. The blood sample was drawn without stasis from an antecubital vein.

Step 2, 'sea level, exercise'. The subjects initially worked six minutes on the bicycle ergometer with loads from 147 watts to 196 watts to produce stable submaximal heart rates between 130 and 150 beats per minute. Then the work load was increased by 50 watts every second minute in order to produce near maximum heart rates, $165-185$ beats per minute. Electrocardiograms were registered each minute and also continuously displayed on an oscilloscope. The retinas in both eyes were photographed immediately upon cessation of work.

Step 3, 'altitude, rest'. Fundus photographs were taken after 10 minutes rest in a sitting position at a simulated altitude of $15,000 \mathrm{ft}$ (4,572 m).

Step 4, 'altitude, exercise'. The same work test as described in 'sea level, exercise' was performed at $15,000 \mathrm{ft}$ simulated altitude, except that the initial six minutes of workload ranged from 98 watts to 147 watts. Immediately following the exercise test, fundus photographs were taken.

\section{Calibre measurement technique}

Fundus photography of both eyes was performed with a Zeiss fundus camera with a $30^{\circ}$ illuminating field of the retina. An interference filter with maximum transmission peak at $535 \mathrm{~nm}$ was inserted in the light path, and a $35 \mathrm{~mm}$ Kodak Plus-X Panchromatic films was used. A 'standard' field of the retina was produced by centering the photograph at onehalf the distance between the fovea centralis and the temporal edge of the optic disc. The films were processed in such a manner that films taken from each subject, before and 
after high altitude exposure, were developed together in the same procedure.

A high-precision and computerised scanning densitometer was used directly on the negatives to determine the calibre of retinal vessels. This technique has been described previously. ${ }^{13-15} \quad$ In summary, transformation from film density into a linear intensity scale was obtained by photographing a 48 step density wedge on film, and by developing the grey-scale film with each experimental film. The densitometer used has a positional accuracy of one micron $(\mu \mathrm{m})$, and a typical scan profile across a retinal vessel is illustrated in Figure 1 . The average intensity difference between the background retina, averaged for both sides, and the blood column is denoted $I_{0}$. The width of the retinal vessel (= width of the blood column), $\mathrm{W}_{\mathrm{o}}$, is always read, by the computer, at half the intensity of $\mathrm{I}_{\mathrm{o}}$, making the width determinations non-biased and independent of any intensity variations in the photograph.

In both eyes of the subjects we studied all sizes of arteries and veins by choosing large, middle-sized and small vessels from all four retinal quadrants. We preferably selected vessels having a straight course in the retina. By a specially designed accessory to a Nikon Profile projector, a precision moveable arm with a thin razor edge, identification marks were cut directly in the emulsion of the films. ${ }^{13}$ These marks denoted the starting point of the scanning, and the transmission coefficient of the negatives was sampled and digitised at 2 $\mu \mathrm{m}$ intervals. The scanning aperture was $5 \mu \mathrm{m}$

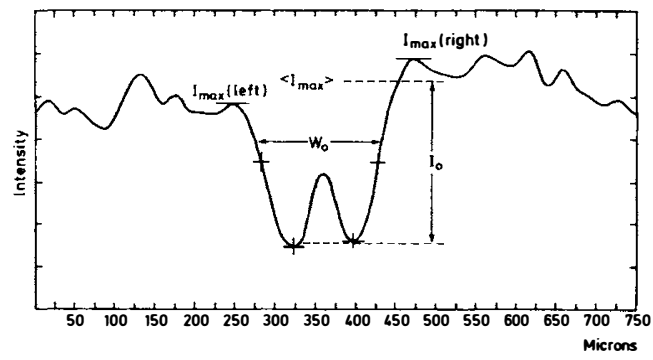

Fig.1. A microdensitometric scan across a retinal vessel in a fundus photograph. The vessel absorption, $I_{o}$, is measured from an averaged background intensity level, $\left(I_{\max }\right)$, and the width of the blood column, $W_{o}$, is measured at half minimum intensity of $I_{o}$. The retinal background on both sides of the blood column and the central light reflex is also seen. wide (in the scanning direction) and the length used was $250 \mu \mathrm{m}$. Twelve arterial and 12 venous sites in each eye were analysed throughout the eight experimental situations, four before and four after the high altitude exposure. From a total of 96 arteries $(12 \times 8)$ and 96 veins analysed at the start of the study, 'sea level, rest' before acclimatisation, 93 arteries and 91 veins were identified and found measureable throughout the study.

\section{Statistics}

The calibre measurements at 'sea level, rest' before acclimatisation were used as baseline values. The percentage change at each vessel site and its standard deviation (SD) was determined in all experimental situations, and we averaged changes at each vessel site in both eyes in each subject. In order to decide whether a change was significant, a two-sided Wilcoxon signed rank test was used, accepting $5 \%$ as the level of significance. Since the data in this study are based on only four subjects, the $P$-values are calculated for each subject (single case study). ${ }^{16}$

In order to illustrate the average vascular responses of the various experimental conditions, we also present the mean values for all arteries $(n=93)$ and veins $(n=91)$.

\section{Results}

The acclimatisation period of the subjects consisted of seven weeks of high altitude climbing, carrying backloads weighing 15-27 $\mathrm{kg}$. Starting the climb at $800 \mathrm{~m}$ they reached the altitude of $5,850 \mathrm{~m}$ (Fig. 2), including frequent dashes to higher levels. On average, they ascended $180 \mathrm{~m}$ per day. The subjects were exposed to considerable physical strain and all experienced symptoms of mountain sickness (nausea, Cheyne-Stokes respiration, insomnia, and headache). The oldest subject experienced symptoms above $2,000 \mathrm{~m}$, the others above $4,500 \mathrm{~m}$.

The post-descent medical examination and tests were conducted eleven days after terminating the expedition in three subjects and one week later in the oldest participant. All subjects were at this time in good health, although high altitude retinal haemorrhages were found in both eyes in the 42 year old subject (no. 2). ${ }^{11}$ Average changes in haem- 


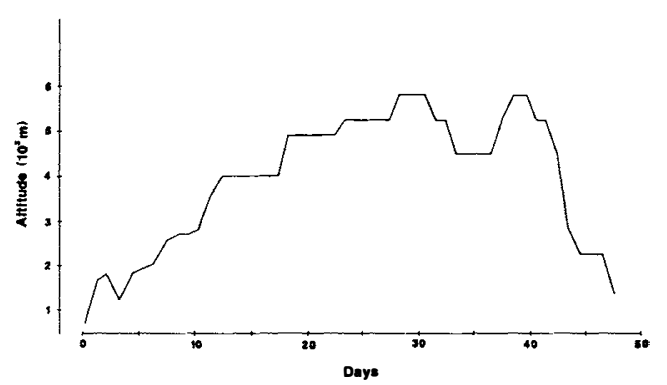

Fig. 2. Altitude profile.

atological parameters, in systemic blood pressure and in intraocular pressure are presented in Table I. Demonstrating altitude acclimatisation, $\mathrm{Hgb}$ increased from 14.8 to $16.1 \mathrm{~g} / \mathrm{dl}(P<0.05)$ while PCV increased from 44.4 to $48.5 \%$ (n.s.). Systolic blood pressure dropped from 142.0 to $118.0 \mathrm{mmHg}(P<0.05)$ while diastolic pressure fell from 80.0 to 77.7 $\mathrm{mmHg}$ (n.s.). A small reduction in intraocular pressure was found (n.s.).

At baseline, 'sea level, rest', before the mountain climbing, the mean $( \pm S D)$ and range of calibres (Wo) of all arteries $(n=93)$ and veins $(n=91)$ were $90.0 \pm 26.3(42-167)$ $\mu \mathrm{m}$ and $102.5 \pm 43.1(41-213) \mu \mathrm{m}$, respectively. The number of vessels analysed throughout the study were: arteries: $n=23$ in subjects no. $1-3$ and $n=24$ in no. 4 , and veins: $\mathrm{n}=22$ in no. $1, \mathrm{n}=26$ in no. $2, \mathrm{n}=25$ in no. 3 , and $n=18$ in no.4. Table II presents the mean percentage change in calibre $( \pm$ SD) before and after acclimatisation. Although a large variance was observed within each subject a consistency of response from individual to individual was found in the various experimental conditions. In Figure 3 (arteries) and 4 (veins) we illustrate the vascular responses by showing the mean percentage change in all vessels from the four participants. No statistical evaluations were performed on these results.

Physical exercise at sea level, before acclimatisation, constricted the arteries by $-1.9 \%$ (Fig. 3). During acute hypoxia $(15,000 \mathrm{ft})$ at rest the arteries dilated $9.4 \%$. When hard physical exercise was superimposed on the hypoxic dilated arteries, the dilation was reduced to $6 \%$.

After altitude acclimatisation, the exercise at sea level constricted the arteries even more:
$-5.4 \%$, compared to $-1.9 \%$ (before) (Fig. $3)$. This change in response was, in particular, seen in the youngest subject (no. 1), from $-2.5 \%$ (before) to $-8.4 \%$ (after) (Table II). At rest at $15,000 \mathrm{ft}$, the hypoxia dilated the arteries less: $6.4 \%$ (after) and $9.4 \%$ (before). The mountain exposure had also conditioned the arterial response to physical exercise at $15,000 \mathrm{ft}$. Superimposed exercise on hypoxia, dilated the arteries from $6.4 \%$ to $8.4 \%$ (after) compared to a constriction from $9.4 \%$ to $6 \%$ (before).

In veins (Fig. 4), a small dilation, $1.1 \%$, was indicated at rest after altitude acclimatisation. The constriction seen during physcial work at sea level before acclimatisation, $-3.3 \%$, failed to occur after acclimatisation ( $0.2 \%)$. No difference in response to acute hypoxia at rest was found, $8.1 \%$ (before) to $8 \%$ (after). As in the case of arteries, superimposed physical exercise on hypoxic dilated veins, after acclimatisation, further increased the dilation, from $8.4 \%$ (before) to $13.7 \%$ (after). This increase in response (i.e. comparing before and after acclimatisation) was very consistent (Table II) and showed statistical significance in three of the four subjects: no. 1 $5.4 \%$ to $14 \%(P<0.001)$, no. $34.8 \%$ to $11.4 \%$ $(P=0.002)$, and no. 4 : 10.6 to $16.6(P=0.003)$.

\section{Discussion}

\section{Before acclimatisation}

(1) Sea level. The most characteristic systemic effects of dynamic muscular work are increased cardiac output and a moderate or small increase in mean arterial blood pressure. ${ }^{17,18}$ This might result in an overperfusion of the retina unless prevented by autoregulatory mechanisms. The present study has shown that dynamic exercise indicated a small constriction in arteries $(1.9 \%)$ and a larger constriction in veins $(3.3 \%)$. The constriction may signal increased vascular resistance with the purpose of reducing surplus retinal blood flow.

Lanigan et al. ${ }^{19}$ studied effects of static (isometric) exercise on retinal vessels and observed significant constriction in arteries (above $8 \%$ ) and veins (about 4\%). The systemic response of static exercise is typically characterised by a large increase in blood pressure. ${ }^{17,19,20}$ Since a significant correlation 
Table I Haematology parameters, intraocular pressure and blood pressure before and after high altitude acclimatisation (mean $\pm S D$ )

\begin{tabular}{lrc}
\hline & \multicolumn{1}{c}{ Before } & \multicolumn{1}{c}{ After } \\
\hline Haemoglobin $(\mathrm{g} / \mathrm{dl})$ & $14.8 \pm 0.4$ & $16.1 \pm 1.1^{*}$ \\
Packed cell volume $(\%)$ & $44.4 \pm 1.0$ & $48.5 \pm 3.5$ \\
Intraocular pressure $(\mathrm{mm} \mathrm{Hg}) \dagger$ & $12.0 \pm 1.4$ & $11.0 \pm 1.4$ \\
Diastolic blood pressure $(\mathrm{mm} \mathrm{Hg})$ & $80.0 \pm 8.0$ & $77.7 \pm 12.6$ \\
Systolic blood pressure $(\mathrm{mm} \mathrm{Hg})$ & $142.0 \pm 9.0$ & $118.0 \pm 8.5^{*}$ \\
\hline
\end{tabular}

* Statistical significant, $\mathrm{P}<0.05$ ( $\mathrm{n}=$ four subjects).

$\dagger$ Mean values of both eyes.

between brachial blood pressure and ophthalmic arterial pressure is documented, ${ }^{20}$ pressure changes seem important in autoregulatory maintenance of retinal blood flow. In accordance, the static exercise of Lanigan et al. ${ }^{19}$ produced a large constriction of retinal vessels compared to the small constriction produced by the dynamic exercise of the present study.

We have, however, little knowledge of the mechanisms controlling autoregulation of retinal flow. Since the arterial oxygenation during exercise at sea level is adequate, changes in blood gases $\left(\mathrm{O}_{2}, \mathrm{CO}_{2}\right)$ should be of minor importance. The constriction seen during exercise may be mediated by changes in perfusion pressure, induced by either increased intravascular pressure/volume or decreased intraocular pressure, ${ }^{21,22}$ or both. Possibly circulating catecholamines, ${ }^{23}$ related to exercise, may be of some significance. Our results do not, however, reveal details of the nature of the retinal autoregulation.

(2) Hypoxia. Acute exposure to hypoxia at $15,000 \mathrm{ft}(4,572 \mathrm{~m})$ at rest showed $9.4 \%$ and $8.1 \%$ dilation in arteries and veins respectively. A recent study by Fallon et al. ${ }^{7}$ showed similar vasodilation $(8.2 \%$ in arteries and $7.5 \%$ in veins) although they used an isocapnic mixture of nitrogen and air. In both studies the oxygen tension in inspired air was lowered approximately $20 \%{ }^{24}$ Consequently hypobaric hypoxia of $15,000 \mathrm{ft}$ apparently has the same dilating effect on retinal vessels as equivalent normobaric hypoxia at sea level. Acute exposure to moderate hypoxia does not normally affect the blood pressure ${ }^{1,24}$ or the intraocular pressure. ${ }^{25-27}$ Thus hypoxic vasolidation at rest demonstrates a local autoregulatory reponse aimed at increasing blood flow in order to maintain the best possible tissue oxygenation.

Table II Percentage change in calibre of retinal vessels (mean $\pm S D$ ) before and after high altitude acclimatisation in the four subjects (No. 1-4)

\begin{tabular}{|c|c|c|c|c|c|c|}
\hline & \multirow{2}{*}{\multicolumn{2}{|c|}{$\frac{\text { Sea level }}{\text { Exercise }}$}} & \multicolumn{4}{|c|}{ Altitude $(15,000 \mathrm{ft})$} \\
\hline & & & \multicolumn{2}{|c|}{ Rest } & \multicolumn{2}{|c|}{ Exercise } \\
\hline & Before & After & Before & After & Before & After \\
\hline \multicolumn{7}{|l|}{ Arteries: } \\
\hline No. 1 & $-2.5 \pm 7.8$ & $-8.4 \pm 8.9^{* * *}$ & $6.0 \pm 11.7^{*}$ & $5.3 \pm 19.0$ & $4.0 \pm 6.4^{* *}$ & $7.0 \pm 16.8$ \\
\hline No. 2 & $-4.2 \pm 10.3$ & $-5.8 \pm 8.6^{* *}$ & $14.8 \pm 16.3^{* * *}$ & $6.3 \pm 10.5^{* *}$ & $8.9 \pm 8.6^{* * *}$ & $8.4 \pm 12.4^{* *}$ \\
\hline No. 3 & $-2.2 \pm 12.5$ & $-4.6 \pm 11.2$ & $7.5 \pm 9.5^{* *}$ & $1.9 \pm 12.6$ & $1.9 \pm 9.4$ & $5.5 \pm 11.7^{*}$ \\
\hline No. 4 & $1.1 \pm 7.5$ & $-2.7 \pm 10.8$ & $9.4 \pm 9.9 * * *$ & $11.9 \pm 11.4^{* * *}$ & $9.0 \pm 9.7^{* * *}$ & $12.6 \pm 9.4^{* * *}$ \\
\hline \multicolumn{7}{|l|}{ Veins: } \\
\hline No. 1 & $-6.5 \pm 12.4^{*}$ & $-1.1 \pm 14.6$ & $5.0 \pm 13.3$ & $8.7 \pm 17.8^{*}$ & $5.5 \pm 11.9^{*}$ & $14.0 \pm 16.2^{* * *}$ \\
\hline No. 2 & $-1.0 \pm 7.4$ & $1.0 \pm 7.3$ & $12.3 \pm 9.1^{* * *}$ & $9.6 \pm 8.5^{* * *}$ & $13.0 \pm 6.4^{* * *}$ & $13.6 \pm 8.0^{* * *}$ \\
\hline No. 3 & $-7.1 \pm 8.9^{* * *}$ & $-2.2 \pm 11.1$ & $6.2 \pm 10.8^{* *}$ & $1.8 \pm 12.0$ & $4.8 \pm 11.7$ & $11.4 \pm 8.2^{* * *}$ \\
\hline No. 4 & $2.3 \pm 10.5$ & $1.4 \pm 10.4$ & $8.4 \pm 9.7^{* *}$ & $13.2 \pm 9.6^{* * *}$ & $10.6 \pm 9.5^{* * *}$ & $16.6 \pm 11.8^{* * *}$ \\
\hline
\end{tabular}

${ }^{*}: \mathrm{P}<0.05,{ }^{* *}: \mathrm{P}<0.01$, and ${ }^{* * *}: \mathrm{P}<0.001$ show statistical significant changes compared to baseline values at 'Sea level, rest' using mean values of individual vessel sites from both eyes in each subject (n: from 18 to 26 ). 


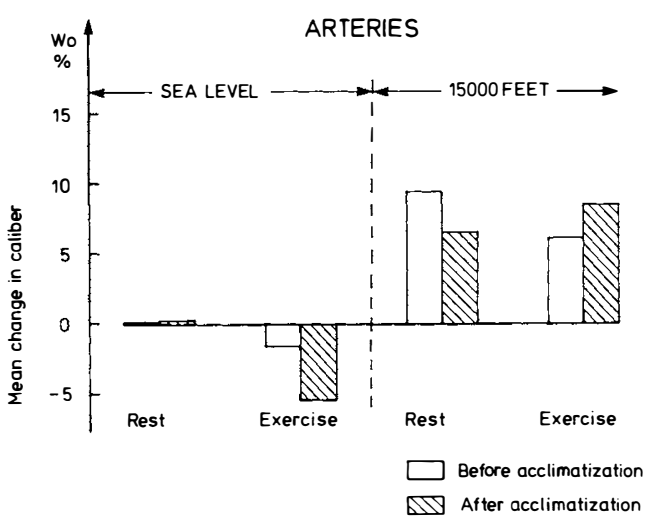

Fig. 3. The mean percentage change in calibre of all arteries $\left(W_{o}\right)(n=93)$ in the four subjects throughout the study. The bar graphs represent the change from the baseline value $=W_{o}$ at 'sea level, rest' before acclimatisation. Open columns show 'before' and hatched columns 'after' acclimatisation. Identical protocols were used before and after seven weeks climbing in Himalaya. Identical vessel sites were measured from fundus photographs of both eyes in each subject at sea level at rest, at sea level performing strenuous dynamic exercise on a bicycle ergometer, at rest in a low-pressure chamber of simulated altitude of $15,000 \mathrm{ft}(4,572 \mathrm{~m})$, and during strenuous dynamic exercise at the same altitude.

(3) Exercise during hypoxia. When physical exercise was performed at $15,000 \mathrm{ft}$ simulated altitude, a compromise between dynamic exercise initiating arterial vasoconstriction and local tissue hypoxia initiating arterial vasolidation resulted. The $9.4 \%$ dilation of arteries at rest was reduced to $6 \%$ by the exercise, the reduction corresponding approximately to the constrictional effect at sea level.

In veins, however, no constriction occurred during exercise at simulated altitude of 15,000 $\mathrm{ft}$, although a constriction occurred in exercise at sea level. At sea level the oxygen content of the blood is unaffected by the exercise and the constriction of veins demonstrates no need for increased blood flow to the retinal tissue. During exercise in the acute hypoxic atmosphere, however, the maximum oxygen uptake is limited by cardiac output, and it falls to about $70 \%$ of the sea level value during exercise at $15,000 \mathrm{ft}^{24}$ The absence of venous constriction may imply that the local oxygen need of retinal tissue has high priority in the autoregulation of retinal circulation, as also demonstrated after acclimatisation.

\section{After acclimatisation}

(1) Sea level. The increase in haemoglobin concentration and packed cell volume demonstrate an increased oxygen capacity of the blood. The observed venous dilation at rest might suggest that acclimatisation has increased the retinal blood volume, possibly through capillary recruitment and lower peripheral resistance. If so, this will correspond to the augmented vascularisation demonstrated in other tissues of altitude acclimatised animals, ${ }^{1}$ including the retina ${ }^{28}$ and the brain. ${ }^{29,30}$ Hensel and Hildebrandt found, in rat and rabbit brains, both increased mean diameter of capillaries and a decreased mean distance between them. ${ }^{30}$ Furthermore, these authors observed that these changes persisted after the return to sea level.

Sea level exercise constricted the arteries more than before the high altitude exposure. This could be a local adjustment of the retina or a response to changes in the systemic circulation, or both. The present study have no data on possible blood pressure changes in response to exercise before and after acclimisation. Vogel et al. found, however, that sea level exercise produced a smaller increase in systolic and mean arterial blood pressures after four weeks stay at $14.100 \mathrm{ft}(4,300 \mathrm{~m})$, compared to sea level exercise before. ${ }^{31}$ This fact, and the significantly lowered blood pressure at rest, suggest a smaller blood pressure increase in exercise after altitude exposure. According to previous observations on relation between calibre of retinal vessels and blood pressure, ${ }^{32,33}$ a reduced pressure level is expected to dilate the arteries, the opposite of

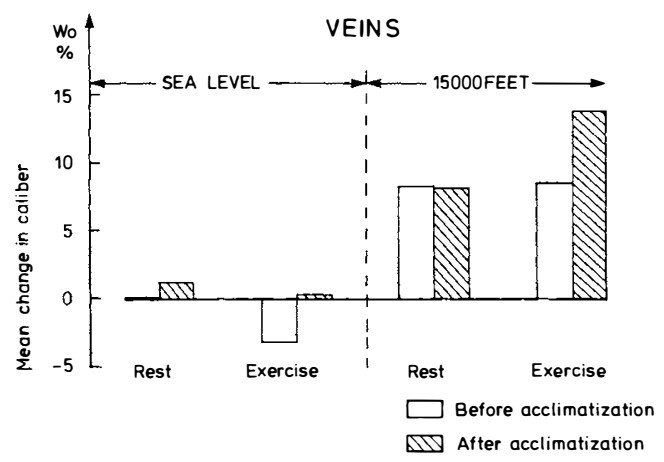

Fig. 4. The mean percentage change in calibre of all veins $(n=91)$ in all four subjects throughout the study. (see the legend to Fig. 3 for further details). 
what was found in the present study. This illustrates the complexity of autoregulation of retinal flow, or, signals the superiority of local regulatory mechanisms compared to systemic mechanisms.

(2) Hypoxia. While no changes were observed in veins, a smaller dilation of retinal arteries were observed at rest in acute hypoxia at $15,000 \mathrm{ft}$, compared to before acclimatisation. This again may reflect that less arterial flow is required to maintain sufficient oxygenation of retinal tissue due to the increased blood oxygen transport capacity.

(3) Exercise during hypoxia. The most conspicuous changes after acclimatisation were seen during physical activity. The superimposed exercise on already hypoxic dilated arteries produced a further increase in calibre, as opposed to the constriction observed before altitude acclimatisation.

The veins dilated even more (averaging $13.7 \%$ ), while no additional dilation was observed with exercise before acclimatisation. Obviously, high altitude acclimatisation has produced an increased state of readiness in coping with acute exercise, especially in an hypoxic atmosphere. If the close relationship found between flow and vessel diameter ${ }^{34,35}$ is also representative for our subjects, a $13.7 \%$ change in calibre will represent a very large increase in blood flow to the retina. The flow increases by approximately the fourth power of the radius of the vessel. ${ }^{34,36}$

Retinal circulation in mountain climbers may be strained to a point where high altitude retinal haemorrhages (HARH) occur, ${ }^{11,37-41}$ as observed in one of the subjects in the present study. The pathogensis of HARH is obscure, although agreement exists on the importance of superimposed physical strain on vulnerable hypoxic dilated retinal vessels. Also puzzling is the observation that HARH often occurs in young $^{41}$ and physically well-trained subjects. ${ }^{10,37,39,40}$ The present study may give a clue to this phenomenon. We observed that the protective constriction of hypoxic vasodilated vessels, seen during exercise before acclimatisation, was replaced by an excessive dilation during exercise after acclimatisation. This change in vascular pattern, particularly observed in veins, would leave the poorly supported veins extra vulnerable to circulatory strain of mountain exposure. Furthermore, young subjects in excellent physical condition are characterised by a considerable increase in cardiac output during exercise, compared to less trained subjects. That is, the younger and more well-trained the more dilated vessels and the more systemic circulatory strain is imposed on the retina during exercise. Possibly, the normal arteriosclerosis of ageing may reduce the hyperpermeability of retinal vessels, and as such, contribute to lower incidence of HARH in older subjects.

The increase in packed cell volume of high altitude adaptation ${ }^{42}$ has the potential disadvantage of increasing blood viscosity. Increased viscosity is associated with venous dilation and impeded blood flow, and this may be of importance in the pathogensis of HARH. ${ }^{10,39,41}$ The small change in packed cell volume from $44.4 \%$ to $48.5 \%$ found in the present study represents the long-term adaptation to chronic hypoxaemia and is probably of minor significance in producing HARH. Reduction of plasma volume and haemoconcentration are seen, however, in acute exposure to hypoxia ${ }^{43}$ and during the initial phase of high altitude exposure, and this may double the normal packed cell volume $(80 \%) .{ }^{41}$ Brendel and Zink ${ }^{41}$ found that subjects developing HARH had a steeper haematocrit rise from the very beginning of altitude exposure. Furthermore, by circumstantial evidence, we have recently shown that a significant change in intravascular flux of water occurs in retinal vessels of young and healthy men on acute (15 minutes) exposure to hypobaric hypoxia of $12,500 \mathrm{ft}$ and $15,000 \mathrm{ft}$ of simulated altitude. ${ }^{44}$ It is also interesting that older subjects do not exhibit early haemoconcentration as do young subjects and may even have an initial increase in plasma volume. ${ }^{42}$ This may also be of pathogenetic significance in explaining why older subjects seem less susceptible of HARH.

Passo et al..$^{22}$ have shown that long-term physical conditioning may affect the baseline intraocular pressure in normal subjects. We have shown that prolonged high altitude acclimatisation, including strenuous exercise, may influence profoundly the ability of the normal human retina to respond to circulatory stress. Both studies indicate that exercise condition- 
ing may significantly influence the experimental results of studies dealing with haemodynamics of retinal flow. Furthermore, the present study may also suggest that long-term physical conditioning has a favourable effect in mobilising spare flow capacity in various vascular diseases of the retina. This is, however, a subject for further research.

\section{References}

${ }^{1}$ Van Liere EJ, Stickney J: Acclimatisation to hypoxia. In Hypoxia. Chicago and London: The University of Chicago Press, 1963. 179-85.

${ }^{2}$ Heath D and Williams DR: Adaptation and acclimatisation. In Man at Altitude. Edinburgh, London, Melbourne, and New York. Churchill Livingstone, 1981. 268-81.

${ }^{3}$ Cusick PL, Benson OO, Boothby WM: Effect of anoxia and of high concentrations of oxygen on the retinal vessels: Preliminary report. Proc Staff Meetings Mayo Clin 1940, 15: 500-2.

${ }^{4}$ Duguet J, Dumont P, Bailliart JP: The effects of anoxia on retinal vessels and retinal arterial pressure. J Aviat Med 1947, 18: 516-20.

${ }^{5}$ Kobrick JL and Appleton B: Effects of extended hypoxia on visual performance and retinal vascular state. J Appl Physiol 1971, 31: 357-62.

${ }^{6}$ Hickam JB and Frayser R: Studies of the retinal circulation in man. Observations on vessel diameter, arteriovenous oxygen difference, and mean circulation time. Circulation 1966, 33: 302-16.

${ }^{7}$ Fallon TJ, Maxwell D, Kohner EM: Retinal vascular autoregulation in conditions of hyperoxia and hypoxia using the blue field entoptic phenomenon. Ophthalmology 1985, 92: 701-5.

${ }^{8}$ Frayser R, Houston CS, Gray GW, et al.: The response of the retinal circulation to altitude. Arch Intern Med 1971, 127: 708-11.

${ }^{9}$ Wiedman M: High altitude retinal hemorrhages. Arch Ophthalmol 1975, 93: 401-3.

${ }^{10}$ Rennie D and Morrissey J: Retinal changes in Himalayan climbers. Arch Ophthalmol 1975, 93: $395-400$.

${ }^{11}$ Brinchmann-Hansen $\mathrm{O}$ and Myhre K: Blood pressure, intraocular pressure, and retinal vessels after high altitude mountain exposure. Aviat Space Environ Med 1989, 60: 970-6.

12 Åstrand PO and Ryhming I: A nomogram for calculation of aerobic capacity (physical fitness) from pulse rate during submaximal work. $J A p p l$ Physiol 1954, 7: 218-21.

${ }^{13}$ Brinchmann-Hansen $\mathrm{O}$ and Engvold O: Microphotometry of the blood column and the light streak on retinal vessels in fundus photographs. Acta Ophthalmol 1986, (Suppl 179) 64: 9-19.

${ }^{14}$ Brinchmann-Hansen O, Heier H, Myhre K: Fundus photography of width and intensity profiles of the blood column and the light reflex in retinal vessels. Acta Ophthalmol 1986, (Suppl 179) 64: $20-8$.

${ }^{15}$ Heier $\mathrm{H}$ and Brinchmann-Hansen O: Reliable measurements from fundus photographs in the presence of focusing errors. Invest Ophthalmol Vis Sci 1989, 30: 674-7.

${ }^{16}$ Sandvik L: Single case studies from a statistician's point of view. Scan J Gastroent 1988, 23: 38-9.

${ }^{17}$ Remky D: Der Netzhautkreislauf bei Muskelarbeit. Ber Deutsch Ophthalmol Gesellsch 1950, 56: 191-4.

${ }^{18}$ Mittl RN, Kurschner D: Ophthalmodynamography in pilots to test internal carotid insufficiency: Comparison of blood-pressure responses. Aviat Space Environ Med 1973, 44: 1067-9.

${ }^{19}$ Lanigan LP, Clark CV, Hill DW: Retinal circulation responses to systemic autonomic nerve stimulation. Eye 1988, 2: 412-7.

${ }^{20}$ Robinson F, Riva CE, Grunwald JE. et al.: Retinal blood flow autoregulation in response to an acute increase in blood pressure. Invest Ophthalmol Vis Sci 1986, 27: 722-6.

${ }^{21}$ Lempert P, Cooper KH, Culver JF, et al.: The effect of exercise on intraocular pressure. $\mathrm{Am} \mathrm{J} \mathrm{Oph-}$ thalmol 1967, 63: 1673-6.

${ }^{22}$ Passo MS, Goldberg L, Elliot DL, Van Buskirk EM: Exercise conditioning and intraocular pressure. Am J Ophthalmol 1987, 103: 754-7.

${ }^{23}$ Ferrari-Dileo G, Davis EB, Anderson DR: Biochemical evidence for cholinergic activity in retinal blood vessels. Invest Ophthalmol Vis Sci 1989, 30: 473-7.

${ }^{24}$ Ernsting J and Sharp GR: Hypoxia and hyperventilation. In Ernsting $\mathrm{J}$, King $\mathrm{P}$, eds. Aviation Medicine. London, Boston, Sydney, Toronto, Wellington: Butterworths, 1988, 45-59.

${ }^{25}$ Wilmer WH and Berens C: The effects of altitude on ocular functions. J Am Med Assoc 1918, 1394-8.

${ }^{26}$ Furuya G: The effects of low pressure on the human eye. I. The effect of low pressure on intraocular tension, particularly in sympathicotonic and vagatonic individuals. Acta Soc Ophthalmol Japan 1936, 40: 2432-43.

${ }^{27}$ Mercier A and Duguet J: Physiopathology of the Flyer's eye. USAF School of Aviation Medicine (transed from Physio pathologie oculaire de l'aviateur). Paris 1947, 3-30.

${ }^{28}$ Huerkamp B and Opitz E: Die Blutgefässe des Augenhintergrundes bei hohenangepasste Kaninchen. Pflueger Arch Ges Physiol 1950, 252: $129-45$.

${ }^{29}$ Diemer K and Henn R: Kapillarvermehrung in der Hirnrinde der Ratte unter chronischem Sauerstoffmangel. Die Naturwissenschaften 1965, 52: 135-6.

${ }^{30}$ Hensel $\mathrm{H}$ and Hildebrandt $\mathrm{G}$ : Organ systems in adaptation: The nervous system. In Dill DB, Adolph EF, Wilber CG eds. Handbook of Physiology: Adaptation to the Environment, section 4, Washington DC, Amercian Physiological Society, $1964,55-72$.

${ }^{31}$ Vogel JA, Hansen JE, Harris CW: Cardiovascular responses in man during exhaustive work at sea level and high altitude. J Appl Physiol 1967, 23: 531-9.

${ }^{32}$ Hill DW and Dollery CT: Calibre changes in retinal arterioles. Trans Ophthalmol Soc UK 1963, 83: 61-71.

${ }^{33}$ Ramalho PS and Dollery CT: Hypertensive retinopathy. Calibre changes in retinal blood vessels fol- 
lowing blood pressure reduction and inhalation of oxygen. Circulation 1968, 37: 580-8.

${ }^{34}$ Riva CE, Grunwald JE, Sinclair SH, Petrig BL: Blood velocity and volumetric flow rate in human retinal vessels. Invest Ophthalmol Vis Sci 1985, 26: 1124-32.

${ }^{35}$ Feke GT, Tagawa H, Deupree DM, et al.: Blood flow in the normal human retina. Invest Ophthalmol Vis Sci 1989, 30: 58-65.

${ }^{36}$ Wise GN, Dollery CT, Henkind P: Physiologic principles. In The Retinal Circulation. New York, Evanston, San Francisco, London: Harper and Row, Publishers, 1971, 83-117.

${ }^{37}$ Schumacher A and Petajan JH: High altitude stress and retinal hemorrhage. Arch Environ Health 1975, 30: 217-21.

${ }^{38}$ Clarke $\mathrm{C}$ and Duff $\mathrm{J}$ : Mountain sickness, retinal haemorrhages, and acclimatisation on Mount Everest in 1975. Br Med J 1976, 2: 495-7.
${ }^{39}$ McFadden DM, Houston CS, Sutton JR et al: Highaltitude retinopathy. J Am Med Ass 1981, 245: $581-6$.

${ }^{40}$ Shults WT, Swan KC: High altitude retinopathy in mountain climbers. Arch Ophthalmol 1975, 93: 404-8.

${ }^{41}$ Zink RA, Schaffert W, Messmer K, Brendel W: Hemodilution, practical experiences in high altitude expeditions. In Brendel W, Zink RA, eds: High Altitude Physiology and Medicine. New York: Springer-Verlag, 1982, 291-7.

${ }^{42}$ Dill DB: Physiological adjustments to altitude changes. J Am Med Ass 1968, 205: 123-9.

${ }^{43}$ Hannon JP, Chinn KSK, Shields JL: Effects of acute high-altitude exposure on body fluids. Federation Proc 1969, 28: 1178-84.

${ }^{44}$ Brinchmann-Hansen O and Myhre K: The effect of hypoxia on the central light reflex of retinal arteries and veins. Acta Ophthalmol 1989, 67: 249-55. 